\title{
Assessing How Sustainability Is Promoted in Ghana's National Urban Policy and Action Plan
}

\author{
Kwasi Anarfi * (D), Chris Shiel and Ross A. Hill \\ Department of Life and Environmental Sciences, Faculty of Science and Technology, Bournemouth University, \\ Fern Barrow, Poole BH12 5BB, UK; cshiel@bournemouth.ac.uk (C.S.); rhill@bournemouth.ac.uk (R.A.H.) \\ * Correspondence: kanarfi@bournemouth.ac.uk
}

Received: 14 July 2020; Accepted: 9 September 2020; Published: 14 September 2020

\begin{abstract}
Managing contemporary and future urbanisation to create sustainable outcomes is a globally acknowledged policy goal. However, despite the increasing uptake and implementation of National Urban Policies (NUPs), little research has explored how these policies incorporate and promote sustainability as a concept in the context of urbanisation. This paper provides a critical analysis of the extent to which sustainability is promoted within urban policy in the context of Ghana. We review Ghana's NUP and supporting Action Plan (AP) to determine whether their initiatives promote sustainability. An evaluation matrix is used to show how the initiatives in the documents align with the dimensions of urban sustainability outlined in the UN-Habitat's City Prosperity Index (CPI); and in addition, consideration is given to how the contents align with the dimensions of the World Bank's Urban Sustainability Framework (USF). The overarching argument that emerges from the analysis is that while Ghana's NUP and AP provide adequate scope and an eclectic mix of initiatives that promote urban sustainability, the sustainability benefits are potentially undermined by factors which include: (i) threats to inclusivity and social sustainability due to the neo-liberal outlook of policy documents; (ii) explicit lack of a poverty reduction strategy; and (iii) lack of environmental performance targets. To this end, suggestions are provided that could potentially enhance the sustainability impacts of Ghana's NUP and AP in the context of urbanisation.
\end{abstract}

Keywords: sustainability; sustainable development; urbanisation; policy; urban; cities; Africa; Ghana

\section{Introduction}

Cities and their urban forms provide visual expressions of policies formulated at the national level and implemented at the local level [1]. Therefore, in an era where more than half of the global population lives in urban areas [2], it can be argued that as much as the forces of urbanisation (including globalisation) shape urban sustainable development, the development of cities tends to reflect the national planning and policy regimes that exist. This is especially relevant when the implications of urbanisation for sustainable development are put in context. On the one hand, urbanisation can promote sustainable development by stimulating the creation of conditions for improved living standards (such as the provision and access to infrastructure, services, jobs, etc.), which are necessary for modern urban living [2]. On the other hand, urbanisation becomes a development quagmire when it deepens socio-economic inequalities, intensifies environmental degradation, magnifies climate change impacts [2], etc. As a result, the urgency of rapid urbanisation and its implications for sustainable development have led to a clarion call for policy prescriptions that will enable relevant decision-makers to address the challenges of rapid urbanisation and, in turn, promote sustainable urbanisation and urban sustainability. In response to this call, the UN-Habitat [3] (para. 1) prescribes the formulation and implementation of National Urban Policies (NUPs) to guide urbanisation and development of urban areas based on the expectation that NUPs will result in: (i) the identification of urban development 
priorities; (ii) the provision of guidance on the future of development; (iii) "the better coordination and guidance of actions"; and (iv) increased and more coordinated investment. However, there is a dearth of research on how sustainability is incorporated within urban policy [4].

In the less-developed regions of the world, especially Sub-Saharan Africa (SSA), where poverty is pervasive, and institutions, as well as regulations guiding urban development are weak [5], the need for solutions to address the challenges of rapid urbanisation is inevitable. Facing the new reality of a more urban (51\%) populace [6], Ghana took a big step forward. In 2012, the Ghanaian Government launched a NUP [7] with a view to steering contemporary and future urbanisation into sustainable outcomes, as well as a supporting Action Plan [8] that detailed the specific actions to be undertaken in order to fully implement the main objectives of the NUP. Importantly, while the extant literature (e.g., $[9,10])$ contributes significantly to our understanding of urbanisation in Ghana, there is little focus on urban policy. This paper attempts to address this knowledge gap, through the study of Ghana's NUP and AP, by examining how sustainability and its representative dimensions are incorporated and promoted through the initiatives in the policy documents. It is worth noting, however, that as the aforementioned policy documents have only been launched in the last decade, the opportunity to judge the policy outcomes is limited. Therefore, the focus of this paper is not to superficially praise or criticise the documents under consideration, but rather to attempt an evaluation of their overarching influence on urban sustainability in Ghana.

\section{Literature Review}

Popularised by the publication of the Brundtland Commission's 'Our Common Future', sustainable development has been defined as "development that meets the needs of the present generation without compromising the ability of future generations to meet their own needs" [11] (p. 8). Also used interchangeably with sustainable development (as is the case in this paper), sustainability simply describes development that balances environmental, social, and economic goals [12]. Despite the widespread uptake of sustainable development as a concept across the globe [13], its definition remains highly contested. This is because the abstract nature of the concept has enabled alternative interpretations of the linkages between economic, environmental, and social aspects of development to flourish and evolve. As a result, many dozens, if not hundreds, of definitions have appeared since the Brundtland Commission first defined sustainable development [14]. Furthermore, the fuzziness of sustainable development as a concept tends to make its constitution open to debate, while there is a paucity of comprehensive frameworks based on which the complexities of sustainable development could be holistically understood due to the concept's transdisciplinary nature [15]. As a result, there is a range of opinions and schools of thoughts on what it means to develop sustainably. Nevertheless, as argued in [16] (p. 248),

"the lack of a precise definition of the term 'sustainable development' is not all bad. It has allowed a considerable consensus to evolve in support of the idea that it is both morally and economically wrong to treat the world as a business in liquidation".

Therefore, drawing predominantly, but not exclusively, on the Brundtland Commission's definition of sustainable development, this paper will present sustainable development (sustainability) as a concept that is underpinned by a desire to provide equal opportunities among and between generations by balancing the demands of economic growth, human well-being, and ecological protection. Especially in the urban context, the interpretation of sustainability as a concept in this paper is one that supports the design and management of urban areas such that urban citizens are able to participate in a modern way of life (e.g., through access to jobs, housing, etc.), while the integrity of the ecological environment is maintained [17].

In the context of sustainability, urban policies have increasingly been used as instruments through which cities have tried to revitalise and reorganise their systems in ways consistent with sustainability principles [18]. The literature is replete with evidence of research carried out on urban sustainability 
policies. For example, the authors of [19], in an explorative study on the pursuit of sustainability in American cities, examined thirteen cities based solely on their urban policies and concluded that only seven of the cities were on a path to sustainability. Others $[20,21]$ have also studied the level of sustainability commitment and activity in urban policies across cities in the United States. The general inference made from these studies is that the extent to which sustainability principles are incorporated in the urban policies of American cities, more often than not, depends on the respective local socio-economic and demographic contexts. However, the author of [22] (p. 488) also evaluated climate action in the urban policies of over 35 small and large cities and concluded that most of the plans "lack the strong actions and political and institutional commitment needed to mitigate emissions". Furthermore, in [4], the sustainability construct in urban policy and metropolitan strategies in Australia was evaluated. The authors concluded that the dominance of urban politics and neo-liberal urbanism hinders the potential of urban policies to stimulate transformative change in the context of sustainability, as in most cases, the priorities of political actors shape the potential of these policies to deliver transformative sustainability change. In this context, according to [23] (p. 89),

"the political precept of neoliberalism is that, while all essential collective decisions need to include the constitutional State, State intervention in the social and economic life should generally be minimal. Rather, the role of the State should be primarily to guarantee and ensure freedom of individual economic agents". Furthermore, in [24] (p. 2), neo-liberal urbanism is defined as "a form of urbanism subordinated to the dictates of capital, where urban powers attempt to position their cities in higher positions of the hierarchical global urban network in which competitiveness is the key".

Critically, the literature suggests that there is insufficient evidence on whether the formulation of urban policies alone provides enough evidence to show that cities are taking sustainability seriously [4] and warrants an exploration of how urban policies incorporate and promote sustainability.

For the cities of SSA, where urbanisation is rapidly taking place, and weak urban management is pervasive [5], it has been suggested that NUPs are critical in harnessing the gains of urban growth and expansion [25]. A response to the international demand for delivering better outcomes in urban areas has, therefore, led to the proliferation of NUPs on the African continent (e.g., Ghana's NUP). Nevertheless, in addition to their scarcity [26], the formulation and implementation of urban policies in Africa over the past few decades have been described as haphazard [27]. This raises serious concerns about the capacity of urban stakeholders to design and deliver essential elements of well-functioning urban areas for a continent that is only halfway through a problematic and risk-replete urban transition [28-32]. Several reasons are usually proffered for the lack of urban-centric policies in African nations. These include weak institutions, inadequate financial resources, outdated regulations, and development agency bias [33-36].

From the point of view of sustainable urbanisation, policy initiatives that direct urban development at a local level are possible solutions for managing future challenges in the transition towards urban sustainability. However, as highlighted earlier, the scarcity of NUPs, or where they exist, the haphazard implementation of NUPs, mean that there is little understanding about how they actually provide improved information and the decision-support tools to adequately deal with the urban sustainability challenges of a rapidly urbanising region such as SSA. This will require an examination of existing NUPs in order to determine the extent to which they address the critical and complex issues facing African governments and planners in capturing the benefits while managing the risks of the continent's urban transition. The literature explored invites the following questions: How is sustainability being promoted in NUPs in Africa? What are the salient 'urban issues' captured in these policies? Which factors potentially undermine the sustainability impacts of NUPs? 


\section{The Ghanaian Urbanisation and Policy Context}

\subsection{Overview of Ghana's Urban Situation}

Ghana represents an important case of the growing trend of rapid urbanisation in SSA. In 1950, only $15.4 \%$ of Ghana's population lived in urban areas. However, by 2010, the urban proportion of Ghana's population had increased to $51.2 \%$; and it is estimated that by 2050 , over $70 \%$ of Ghanaians will live in urban areas [6]. The pace of urbanisation in Ghana, as evidenced by the figures presented above, is rapid. This presents diverse challenges that are potentially inimical to urban sustainable development in Ghana as has also been highlighted in the extant literature. For example, rapid urbanisation exacerbates the housing crisis in Ghana, where a housing stock deficit of 1.7 million units has been reported [37], perpetuating undesirable conditions such as overcrowding [38]. Urban unemployment is widespread and there is an inadequate supply of formal jobs in Ghana [39]. As a result, the informal sector, which is characterised by activities that happen outside the regulative ambit of relevant authorities, is a significant source of employment for urban citizens [39-41]. Poverty and inequality have led to an increased proportion of urban poor in Ghana. For example, in Accra (Ghana's capital city), urban poverty reduced from $23 \%$ in 1992 to $4 \%$ in 1999, before increasing further to $23 \%$ in 2006 [42]. Additionally, climate change processes have increased the occurrence of natural disasters such as floods in urban Ghana [43]. Furthermore, air pollution is intensifying, and in Accra, particulate matter $\left(\mathrm{PM}_{2.5}\right)$ is reported to be higher $\left(30\right.$ to $\left.70 \mu \mathrm{g} / \mathrm{m}^{3}\right)$ than in cities in the Global North $\left(20 \mu \mathrm{g} / \mathrm{m}^{3}\right)$ [44,45]. Consequently, the Ghanaian government has been keen to address the challenges of urbanisation to sustainability through strategies and policies which include the NUP. However, considering the intensive capital requirements needed for urban development $[46,47]$, these strategies tend to have a neo-liberal outlook, thereby exposing urban development to market forces. Aside from the benefits accrued through neo-liberally shaped arrangements such as public-private partnerships (PPP) [48,49], the process of exposing urban development to market forces can be detrimental for sustainability; and in Ghana, the people these arrangements seek to help are sometimes marginalised in the process. For example, as reported in [50], the urban poor in the informal sector are sometimes dispossessed of their lands, which may be their source of livelihood, in urban development and regeneration projects. Furthermore, as in most of the global South, policy-making in Ghana tends to be elitist (e.g., [51]), does not cut across and deliver benefits at various levels (e.g., [52]), and from an overall national development perspective, the programmes addressing urban challenges in Ghana could be seen as a form of 'urban bias' as they potentially favour urban residents compared with rural residents (e.g., [51,53]).

\subsection{Overview of Ghana's National Urban Policy}

An overview of Ghana's NUP is presented as follows. Ghana's urban vision, as articulated in the main goal of the NUP, is "to promote a sustainable, spatially integrated and orderly development of urban settlements with adequate housing, infrastructure and services, efficient institutions, and a sound living and working environment for all people to support the rapid socio-economic development of Ghana" [7] (p. 21). Table 1 outlines the twelve objectives to be pursued in order to realise the goal of the NUP through the AP.

Table 1. Main objectives supporting the goal of Ghana's NUP.

\begin{tabular}{ll}
\hline No & Objectives \\
\hline 1 & "to facilitate balanced re-distribution of urban population" \\
\hline 2 & "to promote a spatially integrated hierarchy of urban centres" \\
\hline 3 & "to promote urban economic development" \\
\hline 4 & "to improve environmental quality of urban life" \\
\hline 5 & "to ensure effective planning and management of urban growth and sprawl, especially of the primate cities and other large urban centres" \\
\hline 6 & "to ensure efficient urban infrastructure and service delivery" \\
\hline
\end{tabular}


Table 1. Cont.

\begin{tabular}{ll}
\hline No & Objectives \\
\hline 7 & "to improve access to adequate and affordable low-income housing" \\
\hline 8 & "to promote urban safety and security" \\
\hline 9 & "to strengthen urban governance" \\
\hline 10 & "to promote climate-change adaptation and mitigation mechanisms" \\
\hline 11 & "to strengthen applied research in urban and regional development" \\
\hline 12 & "to expand sources of funding for urban development and strengthen urban financial management" \\
\hline
\end{tabular}

Source: [7] (pp. 21-22).

In general, the NUP sets out the Ghanaian government's response to the reality that half of Ghana's population lives in urban areas. The NUP is the outcome of a set of activities that began in March 2009 and included: situation analysis and framework for urban development and management in Ghana; stakeholder consultations; technical expert reviews; strategic environmental assessment; stakeholder (public) consultation workshops; and central government consideration and approval [54]. The NUP recognises the need to provide for the increasing urban population vis-à-vis the prevailing urban challenges in Ghana (as outlined in Section 3.1). Consistent with the scarcity of NUPs in Africa [19], the top-down nature of urban governance and lack of effective decentralisation in Ghana mean that municipal authorities do not have the requisite powers to autonomously formulate and implement tailored local urban policies for specific towns or cities. The top-down nature of urban policy formulation and implementation in Ghana is explicitly captured by the author of [55] (p. 51) who writes that:

"Tetteh's analysis (pp. 22-30) of the 'role of Architecture and Planning' in the Future of Our Cities was very insightful. He argues that central government takes the responsibility of planning the cities while city authorities are tasked with controlling the development they did not plan for".

Despite the factors described above, overall, the NUP specifically provides a framework and direction for remedying the challenges in Ghanaian urban areas by addressing urban development and management issues; urbanisation challenges; urban governance issues; urban security issues; urban economic development issues, with emphasis on the informal sector; urban infrastructure provision; urban environmental improvement issues; and urban planning issues $[7,56]$.

\section{Materials and Methods}

This study is part of a wider research project carried out between 2016 and 2020 that aimed to provide an African perspective of urban sustainability based on evidence from Ghana. In this study, we assess Ghana's NUP and the associated AP documents in order to identify how they align with specific elements or indicators that characterise and maximise sustainability in modern urban policy. In doing so, we follow the methods used in [4] in a study of the sustainability construct and incorporation in metropolitan policies in Australia. However, unlike [4] which used an evaluation matrix that was premised on the UN-Habitat's eight emerging trends of urban sustainability as an analysing framework, our evaluation matrix is based on selected dimensions of the UN-Habitat's City Prosperity Index (CPI) [57] which was launched in 2012 to measure sustainability and prosperity in urban areas. Our preference for the CPI over the UN-Habitat's eight emerging trends in this study is because the CPI represents an updated package for measuring urban sustainability and seems to be more comprehensive in terms of the number of items covered by its sub-dimensions which serve as pointers to sustainability. A simple evaluation matrix was constructed to serve as a checklist, where ticks are assigned based on the extent to which the selected CPI sub-dimensions are covered in the NUP and AP of Ghana: zero ticks implies an absolute lack of coverage of the sub-dimension reviewed; one tick implies that the sub-dimension is highlighted but there is a lack of detailed discussion or associated implementation process in the NUP and AP; two ticks imply that there is a detailed or associated implementation process about the specific sub-dimension in the NUP and AP. 
In critiquing the sustainability construct and incorporation in Ghana's NUP and AP, we adopt the World Bank's Urban Sustainability Framework (USF) [58] as the lens of analysis, in contrast to [4] in which an urban political ecology lens was used for the analysis. Therefore, in critiquing how sustainability and its dimensions are infused and promoted in the policy documents, we consider the dimensions of the measuring framework of the USF which are categorised into enabling (Table 2) and outcome dimensions (Table 3).

Table 2. Enabling dimensions and associated goals in the USF.

\begin{tabular}{lcc}
\hline & Enabling Dimensions & Goals \\
\hline 1 & Governance and integrated planning & Achieve integrated well-planned urban development. \\
\hline 2 & Fiscal sustainability & Ensure accountable governance and fiscal sustainability. \\
\hline & & Source: [58].
\end{tabular}

Table 3. Outcome dimensions and associated goals in the USF.

\begin{tabular}{lll}
\hline \multicolumn{1}{c}{ Outcome Dimensions } & \multicolumn{1}{c}{ Goals } \\
\hline 1 & Urban economies & $\begin{array}{l}\text { Attain sustainable economic growth, prosperity, and competitiveness across } \\
\text { all parts of the city. }\end{array}$ \\
\hline 2 & Natural environment and resources & Protect and conserve ecosystems and natural resources into perpetuity. \\
\hline 3 & Climate action and resilience & $\begin{array}{l}\text { Work toward mitigating greenhouse gas emissions while fostering the } \\
\text { overall resilience in cities. }\end{array}$ \\
\hline 4 & Inclusivity and quality of life & $\begin{array}{l}\text { Work toward creating inclusive cities and improving cities' liveability, } \\
\text { focusing on reducing poverty levels and inequality throughout cities. }\end{array}$ \\
\hline
\end{tabular}

Critically, while we recognise the importance of exploring other relevant urban-related documents in this study, it is difficult to achieve that in the present study due to the widely recognised paucity of data on urban areas in Africa and, where data exist, difficulty in accessing them [5]. Therefore, in solely analysing the NUP and AP, we not only concentrate on the most important national documents that have been specifically and strategically formulated to guide Ghana's urban transition, but we also select unarchived documents that are widely available on the government websites, thereby enhancing transparency and replicability in our research. More importantly, as the uptake of NUPs in Africa is scarce and has been described as haphazard where they exist [26,27], a deeper analysis of Ghana's NUP and AP provides a relevant starting point in deconstructing how sustainability is promoted or undermined in urban policy in Africa.

\section{Analysis of Ghana's NUP and AP in the Context of CPI and USF}

\subsection{An Evaluation Matrix Based on the City Prosperity Index}

In Table 4, we present an evaluation matrix which shows how the contents of the NUP and AP align with 18 sub-dimensions of the CPI. From the table, two ticks are assigned to a greater majority (13 out of 18) of the selected CPI dimensions. This highlights the presence of detailed or associated implementation processes in the NUP and AP that relates to the 13 dimensions of the CPI identified in the table. One tick is assigned to four sub-dimensions of the CPI (economic equity; ICT; public spaces; and gender inclusion), meaning that while they were explicitly mentioned, detailed policy initiatives or associated processes were not provided in the NUP and AP. Finally, one sub-dimension (air quality) receives zero ticks as there was no explicit mention, and neither was a detailed set of actions specified. 
Table 4. Evaluation matrix for NUP and AP based on CPI sub-dimensions.

\begin{tabular}{llll}
\hline No & $\begin{array}{l}\text { City Prosperity Index } \\
\text { (CPI Sub-Dimension) }\end{array}$ & Urban Sustainability Framework (USF Dimension) & NUP/AP Score \\
\hline 1 & Economic Strength & Urban economies & 2 \\
2 & Employment & Urban economies & 2 \\
3 & Economic Agglomeration & Urban economies & 2 \\
4 & Housing Infrastructure & Urban economies & 2 \\
5 & ICT & Urban economies & 1 \\
6 & Urban Mobility & Urban economies & 2 \\
7 & Public Space & Inclusivity and quality of life & 1 \\
8 & Safety and Security & Natural environment and resources & 2 \\
9 & Land Use & Urban economies & 2 \\
10 & Economic Equity & Inclusivity and quality of life & 1 \\
11 & Social Inclusion & Inclusivity and quality of life & 2 \\
12 & Gender Inclusion & Natural environment and resources & 1 \\
13 & Air Quality & Natural environment and resources & 0 \\
14 & Waste Management & Climate action and resilience & 2 \\
15 & Energy & Fiscal sustainability & 2 \\
16 & Municipal Finance and Accountability & 2 \\
17 & Participatory and Institutional Capacity & Governance and integrated planning & 2 \\
18 & Governance of Urbanisation & Governance and integrated planning & 2 \\
\hline
\end{tabular}

\subsection{Evaluating the Approach to Sustainability in the NUP and AP Based on the USF}

Following the evaluation matrix presented in the previous Section 5.1, it can be argued that the NUP and AP provide adequate pointers for urban sustainability in Ghanaian policy, particularly in the context of how their contents align with the sub-dimensions of the CPI. The following, therefore, is a critique of the contents of the NUP and AP as discussed through the lens of the dimensions of the USF.

\subsubsection{Urban Economies}

A wide range of urban economic sub-dimensions is captured in the NUP and AP that covers the entire urban economic continuum (i.e., from high-end formal activities to low-end informal activities). For example, in highlighting the potential role of urban areas as engines of economic growth, the NUP makes a case for the designation of some urban areas as 'growth centres' of economic activities and infrastructural development by enhancing their investment portfolios and making provisions to mobilise resources for their investment and infrastructural needs. The NUP and AP further recognise the impact of globalisation and seek to make Ghanaian urban areas globally competitive. At the lower end of the urban economic continuum, the NUP and AP widely capture the urban informal sector. While elaborating all the mechanisms that the NUP and AP proffer as solutions to stimulate urban economic development is difficult, a key theme that emerges is the role of the informal economy. Rather than merely making efforts to reduce informality, the NUP and AP recognise the significance of the informal economy to the overall urban economy, as four of the eight policy initiatives under urban economic development are explicitly based on the informal economy. Specifically, these policy initiatives are intended to: (i) change official attitudes towards informal enterprises-from neglect to recognition and policy support; (ii) ensure that urban planning provides for the activities of the informal economy; (iii) build up and upgrade the operational capacities of the informal enterprises; and (iv) improve funding support for the informal economy. In general, it is evident that the NUP and AP capture elements of the urban economy and propose policy initiatives aimed at promoting economic growth which would, in turn, potentially make Ghanaian urban areas economically competitive.

\subsubsection{Fiscal Sustainability}

Meeting the infrastructural demands for urban areas is capital-intensive, a situation made worse in a fundamentally weak economy such as Ghana $[46,47]$. Therefore, the NUP and AP recognise the issue of urban development finance and fiscal sustainability. For example, the NUP advocates for financially innovative ways of funding urban development and managing the economic sustainability of urban investments. It does this by promoting a project financing approach such as PPP, as an alternative option that will help alleviate the financial pressures on government; and by promoting 
the implementation of fiscal decentralisation proposals through which the central government will devolve its fiscal tools to local metropolitan or municipal authorities, usually in terms of responsibility for revenue mobilisation and spending decisions. Therefore, in the traditional Ghanaian setting where the central government is the main financier of urban services and projects, the NUP and AP recognise the need to find fiscally sustainable means of providing the requisite finance to meet the needs of a growing urban population.

\subsubsection{Inclusivity and Quality of Life}

The housing situation in Ghana is used as a demonstrable exemplar to assess the quality of life. Therefore, from a housing perspective, the NUP and AP give explicit policy support for the provision of housing infrastructure for urban citizens. Accordingly, the NUP advocates for an enabling environment in order to propel private sector delivery of affordable housing in Ghana's urban areas. At the same time, the NUP and AP make a case for the upgrading of slums in urban areas and promote private sector involvement in slum upgrade and redevelopment. This shows that the Ghanaian government, through the NUP and AP, recognises the urgency of the housing situation in Ghana (as evidenced by the reported national housing stock deficit of 1.7 million units) and how it impacts quality of life for urban citizens in Ghana. In terms of inclusivity, the pervasiveness of poverty in Ghana has already been highlighted in this paper. However, there is an inadequate explicit focus on poverty reduction in the NUP. While it can be suggested that some of the objectives of the NUP, including, for example, "promoting urban economic development", may lead to poverty reduction, and others such as slum upgrade and the policy initiatives regarding informality may have the urban poor as intended beneficiaries, critically, there was no detailed breakdown or specification of actions to be carried out to mitigate or reduce urban poverty in a coherent way.

\subsubsection{Natural Environment and Resources}

From an urban environment perspective, the NUP seeks to "improve the environmental quality of urban life". Four of the policy initiatives captured in the AP focus on sanitation and waste management. Policy initiatives for creating environmental awareness through public education, as well as environmental management in mining towns, are also captured. The remaining initiatives focus on the protection of environmentally sensitive sites such as wetlands or coastal areas. Furthermore, while 12 policy initiatives were outlined in the AP to cater for the urban environment, there were no environmental targets set in the NUP and AP. To illustrate, while four of the policy initiatives focused on waste management, no target is captured; for example, the NUP and AP do not indicate a target to suggest that Ghana intends to hypothetically achieve $10 \%$ urban plastic waste recycling by a particular year.

\subsubsection{Climate Action and Resilience}

Ghana's NUP tackles climate change with a policy objective as follows: "to promote climate-change adaptation and mitigation mechanisms". Consequently, the contents of the NUP and AP show that the emphases on urban climate action are for public education on climate and energy conservation, cleaner technologies, emission control, institutional governance, and coastal or wetland management. However, a striking feature of the climate-related policy objective, as captured within the NUP and AP, is the lack of specific targets for climate change action (e.g., emission reduction targets). For example, none of the policy initiatives under climate makes mention of greenhouse gas (the main proponent in the climate change conversation) or provides any targets for their reduction. Furthermore, rather than provide concrete evidence-based measures, the initiatives promoted in the NUP and AP to manage climate change are somewhat vague. For example, one of the key activities to encourage the progressive reduction of hazardous substances by industry is to "apply appropriate and deterrent sanctions to defaulting firms or companies". However, relevant pollutant or climate emission targets based on which the proposed punitive measures will be applied are hardly mentioned. 


\subsubsection{Governance and Integrated Planning}

Ghana's NUP and AP take into cognisance the role of effective governance and planning in dealing with the challenge of population growth and development pressure due to rapid urbanisation. One of the key features of the NUP is the introduction of two cross-cutting initiatives which are intended to achieve multiple objectives namely: The Land Use and Spatial Planning (LUSP) Bill, and Development Guidelines. Passed as the LUSP ACT, 2016, it essentially provides revised legislative foundations based on which sustainable development of land and human settlements will be pursued. The Development Guidelines serve as instruments for the steering of spatial development and comprise planning models, planning standards, and land-use zoning regulations. The planning models captured in the NUP are presented in Table 5. Overall, this demonstrates that the Ghanaian government, through the NUP and $\mathrm{AP}$, recognises how achieving sustainable urbanisation will require integrating national and urban development through the balancing of national and local interests.

Table 5. Planning models captured in Ghana's National Urban Policy.

\begin{tabular}{ll}
\hline Planning Model & Coverage \\
\hline 1.National Spatial Development Framework & National. \\
2. Regional Spatial Development Framework & Administrative regions, sub-region, multi-region. \\
3. District Spatial Development Framework & District, multi-district. \\
4. Structure Plan & District, multi-district, sub-district. \\
5. Local Plan & Sub-districts (specific localities). \\
\hline
\end{tabular}

Source: [7].

\section{Discussion}

\subsection{Sustainability Coverage in Ghana's NUP and AP}

How sustainability and its dimensions in urban policy are framed and understood at the national level will eventually determine the extent of adherence or effectiveness at the local level (e.g., [1]). In the specific context of how the contents of Ghana's NUP and AP align with the selected sub-dimensions of the City Prosperity Index, our analysis demonstrates that the NUP and AP provide adequate scope for urban sustainability since there is a significant alignment with the selected sub-dimensions of the CPI. Conspicuously missing (as shown in Table 4), however, is an explicit focus on 'air quality' in the NUP and AP. One may suggest that the significance of such an omission might be mitigated by the existence of broad policy goals such as "to improve the environmental quality of life". However, to a small extent, we argue that it is rather a reflection of the tendency for urban policies to be vague in the context of sustainability. This is especially true when we consider how, for example, the literature [44] has highlighted the increased incidence of air pollution in urban Ghana; as well as the significance of air quality in terms of the emission of pollutants such as greenhouse gases and their implications for sustainability in urban areas. Essentially, the analysis provided, albeit minimally, lends credence to the suggestion about the haphazardness of urban policy formulation and implementation that is common in most of SSA [27], which includes Ghana.

\subsection{The Policy Approach to Sustainability Based on the Dimensions of the World Bank's USF}

\subsubsection{Urban Economies}

In the context of urban economies, this analysis demonstrates that the NUP and AP provide a strong impetus for economic growth which could, in turn, potentially lay the foundation for sustainable development in Ghana's urban areas. Particularly regarding the urban informal economy, the analysis gives cognisance to the idea that rapid urbanisation in Ghana will render it difficult to create adequate productive employment opportunities to meet the demands of an increasingly urban population [39]. The analysis highlights how informality is not ephemeral but rather a mainstay in the economic space 
in Ghana, thereby warranting policy support for the informal sector that ensures that its positive contributions to the wider urban economy are maximised (as evidenced in the NUP and AP). It is worth noting, however, that the significant attention given to informality in the NUP and AP marks a shift away from elite policy-making, see [51], and also promotes social development by ensuring that the interests of the most vulnerable urban citizens are captured in national policy-making. However, we are also of the opinion that when the focus on urban informality is considered vis-à-vis the equally important need to develop Ghana's rural areas, the NUP and AP could be characterised as examples of 'urban bias' as the policy initiatives potentially change the development conditions in favour of urban residents $[51,53]$. This could give further impetus to rural-urban migration, potentially magnify the pace of urbanisation to unsustainable levels, and undermine urban sustainability.

\subsubsection{Fiscal Sustainability}

Considering the fiscal sustainability dimension, the analysis demonstrates the commitment of the Ghanaian government to ensure that urban development is financed in an efficient and sustainable manner; for example, through PPP [48,49]. However, the proposals outlined for financing urban development in Ghana present both opportunities and challenges that will either enhance or undermine urban sustainable development. For example, the fiscal decentralisation promoted in the NUP and AP could allow revenue to be mobilised and spending decisions made based on locally determined needs and priorities. Challenges could, however, arise where the devolution of fiscal tools threatens macro-economic stability; for example, where the local development priorities of a municipal authority (which are dynamic) do not align with the overall national sustainable development goals.

\subsubsection{Inclusivity and Quality of Life}

In terms of inclusivity and quality of life, the analysis, by focusing on urban housing, highlights the urgency and measures promoted in the NUP and AP to improve the housing situation for urban citizens in Ghana. However, we suggest that an apparent threat to inclusivity and, by extension, the sustainability outcomes of the NUP and AP, is the neo-liberal outlook of the policy initiatives [48,49]. For example, considering slum upgrade, there is a possibility that the pursuit of often capital-intensive redevelopment projects could marginalise the urban poor who are usually the intended beneficiaries of such efforts and make them landless in the process [50]. This assertion is consistent with the suggestion in [4] on how the dominance of neo-liberal urbanism can impede the potential of urban policies to deliver transformational change in the context of sustainability. Furthermore, while we admit that the wider policy initiatives (e.g., support for informal sector, upgrade of slums, etc.) might contribute to overall urban poverty reduction, we argue that inclusivity and quality of life are potentially undermined in the NUP and AP as the analysis shows that they do not adequately address urban poverty in more explicit ways. This, therefore, reflects the need to formulate urban policy in a way that ensures sustainability through the incorporation of explicit inclusivity measures, including a poverty reduction strategy, in policy design.

\subsubsection{Natural Environment and Resources}

Urbanisation exerts varying degrees of pressure on the natural environment in urban Ghana [43]. While the contents of the NUP and AP highlight the actions being pursued to manage the delicate trade-offs between the anthropogenic impacts of urbanisation and the threats to the integrity of the natural environment, the analysis suggests that policy initiatives outlined in the NUP and AP do not have accompanying targets to serve as benchmarks for environmental action. In our view, the absence of such targets makes it difficult to decipher how the policy initiatives will contribute to urban sustainability. This shows that the NUP and AP provide a broad guiding framework rather than the means and tools for achieving specific environmental targets. Critically, however, the analysis makes it evident that the NUP and AP provide a strong starting point for mainstreaming environmental concerns into urban policy and decision-making. 


\subsubsection{Climate Action and Resilience}

As a country that is expected to exceed an urbanisation level of $70 \%$ by 2050 [6], one of Ghana's most significant challenges is managing the trade-off between urban growth and climate change processes [43]. The analysis demonstrates that the NUP and AP provide strategies for climate change mitigation in Ghana's urban areas. However, the insight gained from the analysis about the lack of emission targets for climate change action in the NUP and AP provokes this question: are Ghanaian urban areas ready for climate change? This is because the apparent lack of urban-related emissions targets or data for urban climate change action makes it difficult to determine whether the climate change-related initiatives in the NUP and AP encompass the necessary elements that are needed for successful climate change mitigation and adaptation in Ghana's urban areas, especially in ways which could eventually contribute to urban sustainability. While we recognise that mitigating climate change requires a multi-sectoral approach where various sectors (e.g., the power generation and manufacturing industries) may already have implemented national plans towards greenhouse gas reduction and climate change mitigation, the lack of targets in critical documents such as the NUP and AP makes it difficult to determine the ambitiousness of the policy initiatives, and the national capacity thereof, to achieve them. Therefore, the analysis is consistent with the views shared in [7] (p. 488) in which it is argued that the majority of urban plans "lack the strong actions and political and institutional commitment need to mitigate emissions". Based on the analysis presented, it remains to be seen, crucially, what the capacity of local authorities for climate action in Ghana's urban areas will be if national-level urban policy documents are limited in scope in terms of progress and targets for climate change.

\subsubsection{Governance and Integrated Planning}

The analysis outlines the Ghanaian Government's commitment to the effective governance and planning of urbanisation by introducing cross-cutting legislative instruments and development guidelines. In particular, the development guidelines, which are expected to provide a framework for development planning from the national to the local levels, may address the widely-held view about the tendency for policies to fail due to the limited extent to which policy elements cut across different levels or departments [52]. Therefore, while the effectiveness of the legislative instruments and development guidelines proposed in the NUP cannot be determined at the moment, they highlight the critical steps being made to address the institutional capacity weaknesses that are known to undermine sustainable urbanisation in SSA and, by extension, Ghana.

\section{Recommendations and Limitations}

This study is framed within the wider discussion on how policy can contribute to sustainable development. Therefore, to address the challenge of maximising the sustainability impact of policy in the context of rapid urbanisation, the following two steps are suggested. Firstly, the absence of relevant benchmarks or emissions targets shows that there is an apparent lack of data on urban systems in Ghana (e.g., climate-related data) which can be used to inform policy. This makes it relevant for the authorities to conduct research that helps to develop Ghana-specific indicators and establish criteria, based on which progress to sustainability could be evaluated for policy-making purposes. Secondly, the pervasiveness of poverty in urban Ghana and its importance for sustainability have been highlighted in this study. Therefore, considering the explicit lack of poverty focus in urban policy documents studied, it is imperative for relevant authorities to restructure aspects of the policies and situate them within a coherent poverty reduction strategy.

Despite the potential significance of our study, we report some limitations. Firstly, in interpreting the insights of this analysis, it must be acknowledged that our study focused solely on the NUP and $\mathrm{AP}$ as the sources of data due to the paucity and difficulty in accessing data in Ghana. While focusing on Ghana's NUP and AP ensured that we analysed the most relevant and accessible urban policy 
documents, further research could expand the scope of analysis to include other policies that may be influenced by the NUP (e.g., Ghana's National Housing Policy), and also to deepen urban policy research by providing a comparative analysis of urban policies implemented in other countries. Secondly, our study adopted the UN-Habitat's CPI and World Bank's USF to analyse data and frame discussions on the sustainability construct and incorporation in Ghana's urban-related policy documents. This means that our analyses were restricted to the dimensions captured in the aforementioned index and framework. However, the potential bias that the restriction to the CPI and USF may have induced in our analysis is potentially mitigated by the reality that the CPI and USF are relevant, reliable, and internationally accepted. Future research could, however, consider conceptualising and developing other indices for urban policy analysis in Ghana, as well as framing urban policy analysis based on other relevant sustainability-related theoretical frameworks. Thirdly, although poverty and neo-liberalism emerged as critical to urban sustainability in Ghana in this analysis, a deeper consideration of these concepts was limited by the scope of our study. Therefore, future research could consider the nexus between poverty, neo-liberalism, and sustainability in the context of urban policy. Fourthly, future work could improve on the matrix developed in this study and test its applicability, as a means of establishing a checklist of the representative dimensions of sustainability in urban policies in different countries. Finally, as our analysis focused on how sustainability is incorporated and promoted in urban policy, further research is needed to explore the factors that challenge sustainability operationalisation in urban policy.

\section{Conclusions}

This study contributes to our understanding of policy responses to urbanisation, and it assesses how sustainability and its dimensions are promoted within Ghana's National Urban Policy and Action Plan. On the whole, the study shows that, to a large extent, the NUP and AP incorporate elements that promote sustainability when considered strictly within the dimensions of the CPI. Nevertheless, the study also highlights how critical dimensions of the CPI such as air quality are not explicitly captured. This, we argue, could be due to the tendency of urban policy to be vague, thereby making certain critical elements inconspicuous and potentially undermining alignment with sustainability. When the contents of the NUP and AP are considered through the lens of the USF, the study shows that the NUP and AP put forward sets of actions which could promote urban sustainability, and prominent actions among them include: (i) urban economic growth initiatives with a strong focus on the informal sector; (ii) sustainable financing of urban development through measures such as PPP; (iii) improving the quality of life by providing affordable housing; (iv) promoting environmental quality and creating environmental awareness; (iv) climate change mitigation by promoting cleaner technologies, emission control, etc.; and (iv) providing governance and legal framework for managing urbanisation. However, we highlight certain factors which could undermine the sustainability impacts of the policy initiatives and these include: (i) the neo-liberal outlook of the NUP and AP which, if not well managed, could threaten inclusivity of marginalised citizens; (ii) the lack of a coherent poverty reduction focus; and (iii) the lack of an explicit outline of environmental and emission targets. Therefore, we conclude that while Ghana's NUP and AP are evidence of the right national strategy for managing the country's current and future urbanisation into sustainable outcomes, critical issues such as the lack of emission targets need to be addressed in order to maximise the sustainability impacts of the policy initiatives. Essentially, by assessing Ghana's NUP and AP, our study makes a contribution to scholarly literature as it frames a perspective on the extent to which sustainability is embedded in policy-making for urban sustainability in Ghana, which, to the best of the authors' knowledge, is not evidently captured in the extant literature.

Author Contributions: All authors contributed in the development of the current paper. Investigation, K.A.; Writing-original draft preparation, K.A.; Writing—review \& editing, C.S. \& R.A.H.; Supervision, C.S. and R.A.H. All authors have read and agreed to the published version of the manuscript. 
Funding: This research received no external funding. The manuscript preparation was supported by Department of Life and Environmental Sciences (Bournemouth University) QR Fund award. The APC was funded through Bournemouth University's Open Access Fund.

Acknowledgments: This research was supported by the Bournemouth University Vice Chancellor's PhD Scholarship awarded in 2016. We would like to thank the anonymous reviewers for their useful comments and suggestions.

Conflicts of Interest: The authors declare no conflict of interest.

\section{References}

1. Uitermark, J. The genesis and evolution of urban policy: A confrontation of regulationist and governmentality approaches. Political Geogr. 2005, 24, 137-163. [CrossRef]

2. Cui, X.; Fang, C.; Liu, H.; Liu, X. Assessing sustainability of urbanization by a coordinated development index for an Urbanization-Resources-Environment complex system: A case study of Jing-Jin-Ji region, China. Ecol. Indic. 2019, 98, 383-391. [CrossRef]

3. UN-Habitat: Pursuing Sustainable Urban Development through Urban Policies, Regional and Metropolitan Planning. Available online: https://open.unhabitat.org/node/36544 (accessed on 20 March 2020).

4. Davidson, K.; Arman, M. Planning for sustainability: An assessment of recent metropolitan planning strategies and urban policy in Australia. Aust. Plan. 2014, 51, 296-306. [CrossRef]

5. Smit, W.; Parnell, S. Urban sustainability and human health: An African perspective. Curr. Opin. Environ. Sustain. 2012, 4, 443-450. [CrossRef]

6. Cobbinah, P.B.; Erdiaw-Kwasie, M.O.; Amoateng, P. Africa's urbanisation: Implications for sustainable development. Cities 2015, 47, 62-72. [CrossRef]

7. Ministry of Local Government and Rural Development. Ghana National Urban Policy Framework. 2012. Available online: https:/www.nalag-ghana.org/wp-content/uploads/2019/03/national_urban_policy_ framework_ghana_2012.pdf (accessed on 20 March 2020).

8. Ministry of Local Government and Rural Development. National Urban Policy and Action Plan. Available online: http://www.ghanaiandiaspora.com/wp/wp-content/uploads/2014/05/ghana-national-urban-policyaction-plan-2012.pdf (accessed on 3 March 2020).

9. Toure, S.I.; Stow, D.A.; Clarke, K.; Weeks, J. Patterns of land cover and land use change within the two major metropolitan areas of Ghana. Geocarto Int. 2018, 35, 209-223. [CrossRef]

10. Anarfi, K.; Hill, R.A.; Shiel, C. Highlighting the Sustainability Implications of Urbanisation: A Comparative Analysis of Two Urban Areas in Ghana. Land 2020, 9, 300. [CrossRef]

11. Report of the World Commission on Environment and Development [WCED]: Our Common Future; Oxford University Press: London, UK, 1987.

12. Jeronen, E. Sustainability and Sustainable Development. Encycl. Corp. Soc. Responsib. 2013, 2370-2378. [CrossRef]

13. Barkemeyer, R.; Holt, D.; Preuss, L.; Tsang, S. What happened to development in sustainable development? Sustain. Dev. 2014, 22, 15-32. [CrossRef]

14. Kates, R.W.; Parris, T.M.; Leiserowitz, A.A. What is sustainable development? Environment 2005, 47, 8-21.

15. Jabareen, Y. A new conceptual framework for sustainable Development. Environ. Dev. Sustain. 2008, 10, 179-192. [CrossRef]

16. Daly, H. Steady State Economics, 2nd ed.; Island Press: Washington, DC, USA, 1991.

17. Brown, A.M. Uganda's new urban policy: Participation, poverty, and sustainability. In Sustainable Futures: Architecture and Urbanism in the Global South; 2012. Available online: http://www.sfc2012.org/brown.pdf (accessed on 8 August 2020).

18. Portney, K.E.; Berry, J.F. Participation and the Pursuit of Sustainability in U.S. Cities. Urban Affairs Rev. 2010, 46, 119-139. [CrossRef]

19. Portney, K.E.; Cutler, Z. The local non-profit sector and the pursuit of sustainability in American cities: A preliminary exploration. Local Environ. 2010, 15, 323-339. [CrossRef]

20. Portney, K.E. Taking Sustainable Cities Seriously: Economic Development, the Environment, and Quality of Life in American Cities; MIT Press: Cambridge, MA, USA, 2003.

21. Lubell, M.; Feiock, R.; Handy, S. City Adoption of Environmentally Sustainable Policies in California's Central Valley. J. Am. Plann. Assoc. 2009, 75, 293-308. [CrossRef] 
22. Wheeler, S.M. State and municipal climate change plans: The first generation. J. Am. Plan. Assoc. 2008, 74, 481-496. [CrossRef]

23. Obeng-Odoom, F. Neoliberalism and the Urban Economy in Ghana: Urban Employment, Inequality, and Poverty. Growth Chang. 2012, 43, 85-109. [CrossRef]

24. Vives Miro, S. Producing a "successful city": Neoliberal urbanism and gentrification in the tourist city-The case of Palma (Majorca). Urban Stud. Res. 2011, 2011, 1-13. [CrossRef]

25. UN-Habitat: Urbanisation in Africa, African Development Banks. 13 December 2012. Available online: https://blogs.afdb.org/inclusive-growth/urbanization-africa-191 (accessed on 20 March 2020).

26. Turok, I. Turning the tide? The emergence of national urban policies in Africa. J. Contemp. Afr. Stud. 2015, 33, 348-369. [CrossRef]

27. Pillay, U. Urban Policy in Post-Apartheid South Africa: Context, Evolution and Future Directions. Urban Forum 2008, 19, 109-132. [CrossRef]

28. Parnell, S.; Pieterse, E.; Watson, V. Planning for Cities in the Global South. Progress Plan. 2009, 72, $233-248$.

29. Bogaert, K. The Problem of Slums: Shifting Methods of Neoliberal Urban Government in Morocco. Dev. Chang. 2011, 42, 709-731. [CrossRef]

30. Buckley, R.; Kallergis, A. Does African Urban Policy Provide a Platform for Sustained Economic Growth? In The Routledge Handbook on Cities of the Global South; Parnell, S., Oldfield, S., Eds.; Routledge: London, UK, 2014; pp. 173-190.

31. Cheru, F. Structural Transformation in Ethiopia: The Urban Dimension; UN-Habitat: Nairobi, Kenya, 2014.

32. UN-Habitat. State of African Cities 2014: Re-Imagining Sustainable Urban Transitions; UN-Habitat: Nairobi, Kenya, 2014.

33. Bryceson, D.F.; Gough, K.V.; Rigg, J.; Agergaard, J. Critical commentary. The World Development Report 2009. Urban. Stud. 2009, 46, 723-738. [CrossRef]

34. Turok, I.; Parnell, S. Reshaping Cities, Rebuilding Nations: The Role of National Urban Policies. Urban. Forum 2009, 20, 157-174. [CrossRef]

35. Bekker, S.; Therborn, G. Capital Cities in Africa; HSRC Press: Cape Town, South Africa, 2012.

36. Fox, S. The Political Economy of Slums: Theory and Evidence from Sub-Saharan Africa. World Dev. 2014, 54, 191-203. [CrossRef]

37. Ghana Faces Housing Glut—Despite Deficit. Available online: https://www.graphic.com.gh/features/features/ ghana-faces-housing-glut-despite-deficit.html (accessed on 15 January 2019).

38. Yakubu, I.; Akaateba, M.W.; Akanbang, B.A. A study of housing conditions and characteristics in the Tamale Metropolitan Area, Ghana. Habitat Int. 2014, 44, 394-402. [CrossRef]

39. Osei-Boateng, C.; Ampratwum, E. The Informal Sector in Ghana. Available online: https://library.fes.de/pdffiles/bueros/ghana/10496.pdf (accessed on 29 July 2019).

40. Porter, L. Informality, the commons and paradoxes for planning: Concepts and debates for informality and planning. Plann. Theor. Pract. 2011, 12, 112-120.

41. Hormeku, T. The Transformation and Development of the Informal Sector and the Role of Trade Unions. In Proceedings of the OATUU/ILO/ETUF Seminar on "Trade Unions and the Informal Sector", Cairo, Egypt, 4-6 May 1988.

42. UNICEF. Understanding the specifics of urban poverty: A case study from Accra, Ghana. In The State of the World's Children; United Nations Children's Fund: New York, NY, USA, 2012.

43. Okyere, C.Y.; Yacouba, Y.; Gilgenbach, D. The Problem of Annual Occurrences of Floods in Accra: An Integration of Hydrological, Economic and Political Perspectives. Interdisciplinary Term Paper. ZEF Doctoral Studies Programme. Available online: https://www.zef.de/fileadmin/downloads/.../2012_2_ Gilgenbach_Okyere_Yacouba.pdf (accessed on 20 April 2019).

44. Dionisio, K.; Arku, R.E.; Hughes, A.F.; Vallarino, J.; Carmichael, H.; Spengler, J.D.; Agyei-Mensah, S.; Ezzati, M. Air pollution in Accra neighborhoods: Spatial, socioeconomic and temporal patterns. Environ. Sci. Technol. 2010, 44, 2270-2276. [CrossRef]

45. Brauer, M.; Amann, M.; Burnett, R.T.; Cohen, A.; Dentener, F.; Ezzati, M. Exposure assessment for estimation of the global burden of disease attributable to outdoor air pollution. Environ. Sci. Technol. 2012, 46, 652-660. [CrossRef

46. Farvacque-Vitkovic, C.; Raghunath, M.; Eghoff, C.; Boakye, C. Development of the Cities of Ghana Challenges, Priorities and Tools, Africa Region Working Paper Series Number 110; World Bank: Washington, DC, USA, 2008. 
47. Okeke, I.N. Towards a New Growth Path in Africa: A Study of National Urban Policy Responses to Urbanisation; Working Paper; South African Cities Network: Johannesburg, South African, 2014.

48. OECD. Competitive Cities: A New Entrepreneurial Paradigm in Spatial Development. Available online: https://www.oecd.org/cfe/regional-policy/38747575.pdf (accessed on 3 January 2019).

49. Lauermann, J. Urban Managerialism/Entrepreneurialism. In The Wiley-Blackwell Encyclopedia of Social Theory; Wiley-Blackwell: Hoboken, NJ, USA, 2017. [CrossRef]

50. Obeng-Odoom, F. Regeneration for some; degeneration for others. In The Routledge Companion to Urban Regeneration; Leary, M., McCarthy, J., Eds.; Routledge: London, UK, 2013; pp. 189-198.

51. Lipton, M. Why Poor People Stay Poor: A Study of Urban Bias in World Development; Temple Smith: London, UK, 1977.

52. Niyonkuru, F. Failure of Foreign Aid in Developing Countries: A Quest for Alternatives. Bus. Eco. J. 2016, 7 , 1-9. [CrossRef]

53. Majumdar, S.; Mani, A.; Mukand, S.W. Politics, information and the urban bias. J. Dev. Econs. 2004, 75, 137-165. [CrossRef]

54. Awortwi, N. Ghana National Urban Policy: Exercise Fit for Purpose or Another Policy Document on the Shelf? Available online: https://www.urbangateway.org/icnup/sites/default/files/ICNUP\%20Ghana.pdf (accessed on 23 January 2019).

55. Obeng-Odoom, F. The future of our cities. Cities 2009, 26, 49-53. [CrossRef]

56. Habitat III National Report for Ghana. Third United Nations Conference on Housing and Sustainable Urban Development. Available online: http://habitat3.org/wp-content/uploads/Approved-Final-GhanaHabitat3Report.pdf (accessed on 5 May 2016).

57. UN-Habitat: City Prosperity Initiative. Available online: https://unhabitat.org/sites/default/files/2019/02/CPIMETADATA.2016.pdf (accessed on 20 March 2020).

58. World Bank: Urban Sustainability Framework. Available online: http://documents.worldbank.org/curated/ en/339851517836894370/pdf/123149-Urban-Sustainability-Framework.pdf (accessed on 20 March 2020).

(C) 2020 by the authors. Licensee MDPI, Basel, Switzerland. This article is an open access article distributed under the terms and conditions of the Creative Commons Attribution (CC BY) license (http://creativecommons.org/licenses/by/4.0/). 